\title{
Prescribing patterns of antihypertensive medications and blood pressure con- trol among hypertensive patients in a primary care setting in Malaysia
}

\author{
Jun-Ming $\mathrm{Ng}^{1}$, Kok Pim Kua ${ }^{1 *} \&$ Shaun Wen Huey Lee ${ }^{2}$ \\ ${ }^{1}$ Pharmacy Unit, Puchong Health Clinic, Ministry of Health Malaysia, Batu 14, 47000 Puchong, Petaling, Selangor, Malaysia. \\ ${ }^{2}$ School of Pharmacy, Monash University Malaysia, Jalan Lagoon Selatan, 47500 Bandar Sunway, Selangor, Malaysia.
}

\begin{abstract}
:
Aims

This study aims to describe the prescribing patterns of antihypertensive medications and short term outcomes of these patients, defined as repeat blood pressure measurements by a medical professional within 6 months, in a primary care facility in Puchong, located within the state of Selangor in Malaysia.

\section{Methods}

This study was a cross-sectional, retrospective analysis of patients with essential hypertension, aged 18 and above, with blood pressure recorded at least twice within a 6-month period in an urban primary care clinic in Malaysia. Patients with history of co-morbidities were excluded. The prescribing patterns of antihypertensive medications and proportion of patients who achieved blood pressure control of less than 140/90 mmHg were ascertained.

\section{Results}

A total of 200 prescriptions were analysed, including 52.5\% females taking a mean of $1.7(0.7)$ antihypertensive medications with a mean age of 57.9 (12.4) years. Most of the patients were prescribed either a single medication $(\mathrm{n}=90,45.0 \%)$ or two medications $(\mathrm{n}=90 ; 45.0 \%)$ to control their blood pressure. Only 20 patients $(10.0 \%)$ were prescribed three antihypertensive medications. A total of 127 (63.5\%) patients met the blood pressure target of less than 140/90 mmHg. All participants exhibited a significant drop in systolic blood pressure, reducing from $143.0(16.0) \mathrm{mmHg}$ at baseline to $135.3(14.8) \mathrm{mmHg}$ at the end of 6 months $(p<0.001)$. Diastolic blood pressure also decreased significantly from $83.5(11.7) \mathrm{mmHg}$ at baseline to 79.0 (10.2) $\mathrm{mmHg}$ at the end of 6 months $(\mathrm{p}<0.001)$. The choice of antihypertensive medications by the prescribers was compliant with the hypertension guidelines of Malaysia.
\end{abstract}

\section{Conclusion}

The most commonly prescribed antihypertensive class was calcium channel blockers. Significant reduction in blood pressure was observed in patients from baseline to the follow-up visit. Further research of larger sample size and longer monitoring period is necessary to provide more robust epidemiology and drug utilisation data.

\section{Impact of findings on practice statements}

1. Evaluation of medicine prescription patterns allows the monitoring of prescribing practice in a health care setting and facilitates rational use of medicines.

2. Prescribing patterns can elucidate the extent and profile of drug use, trends and compliance with national guidelines.

3. Prescription patterns of antihypertensive medications that are in accordance with guidelines for the management of hypertension improves health outcomes.

4. Patients receive medications appropriate to their clinical needs for an adequate period of time and at good value for money to both the patients and the government health care spending.

Keywords: Hypertension; public health; clinic; prescription; medicine; guideline; cross-sectional retrospective; Malaysia.

*Correspondence: Kok Pim Kua, Pharmacy Unit, Puchong Health Clinic, Ministry of Health Malaysia, Batu 14, 47000 Puchong, Petaling, Selangor, Malaysia; kuakokpim@moh. gov.my 
Received: 2nd February 2020

Accepted: 4th March 2020

Published Online: 12th March 2020

Citation: Ng J-M, Kua K-P \& Lee SWH. Prescribing patterns of antihypertensive medications and blood pressure control among hypertensive patients in a primary care setting in Malaysia. Prog Drug Discov Biomed Sci 2020; $3(1)$ : a0000055. https://doi.org/10.3687/pddbs.a0000055

\section{Introduction}

Approximately one in every two Malaysian adults has hypertension ${ }^{[1]}$ which is recognised as one of the most important risk factors for end-stage organ damage, heart failure, stroke and renal impairment ${ }^{[2]}$. Antihypertensive therapy has been shown to be effective in reducing hypertension-related morbidity and mortality ${ }^{[3]}$. Over the past decade, several clinical guidelines have been published on the management of hypertension ${ }^{[4,5]}$.

The management of hypertension requires, in addition to lifestyle and behavioural modifications, affordable and widely available antihypertensive medications prescribed appropriately in primary health care which represents the first level and main point of contact of patients in Malaysia. While many studies have evaluated guideline adherence in the treatment of hypertension ${ }^{[6]}$, data from Malaysia on prescribing patterns of antihypertensive therapy have thus far been scarce ${ }^{[7]}$. This study aims to report the prescription patterns of antihypertensive medications and the success rate in attaining blood pressure control in a primary care health clinic in Malaysia.

\section{Methods}

This was a retrospective cross-sectional study conducted at Puchong Health Clinic, Malaysia from January 1, 2017 till July 31, 2018. The clinic serves a population of approximately 350,000 and is a typical government-funded primary health care centre in Malaysia. Prescriptions and medical records of patients aged 18 and above diagnosed with essential hypertension and ordered for one to three types of antihypertensive agents, had no secondary causes of hypertension and had no existing co-morbidities (e.g., coronary heart disease, stroke, congestive heart failure, diabetes mellitus, chronic kidney disease, the metabolic syndrome and dyslipidaemia) were screened. Exclusion criteria were those who were diagnosed with resistant hypertension (characterised by failure to achieve a blood pressure goal of less than 140/90 $\mathrm{mmHg}$ while on optimal doses of three different classes of antihypertensive medications, including a diuretic appropriate for kidney function $)^{[8]}$, taking four or more antihypertensive medications or did not have the two blood pressure readings recorded between each clinic visit (follow-up visits at six months apart). For each patient, we documented baseline sociodemographic and clinical data including age, gender, ethnicity, antihypertensive medications used and blood pressure readings. Categorical variables were presented as numbers and percentages, whereas continuous variables were presented as means (standard deviation). We calculated the proportion of patients who had achieved the target blood pressure control of less than $140 / 90 \mathrm{mmHg}^{[9]}$. We assessed the differences in blood pressure readings between baseline and follow-up visit using paired t-tests. A p-value of less than 0.05 was considered statistically significant for all tests. All data were analysed by using IBM SPSS Statistics for Windows, Version 24.0 (Armonk, NY: IBM Corp. Released 2016).

\section{Ethics Statement}

This study was retrospective in design and no ethics approval was necessary. This study was conducted in accordance with the 1964 Declaration of Helsinki and its later amendments or comparable ethical standards and was approved for publication by the National Institutes of Health, Ministry of Health Malaysia (Reference Number: KKM.NIHSEC.800-4/4/1 Jld. 68[54]).

\section{Results}

A total of 200 patients were included in this study, with $105(52.5 \%)$ being female and $142(71.0 \%)$ aged above 50 years. Most of the patients were of Malay and Chinese ethnicity $(86.5 \%)$, taking a mean of $1.7(0.7)$ antihypertensive medications (Table 1). The most commonly prescribed class of antihypertensive medications were the calcium channel blockers, followed by angiotensinconverting enzyme inhibitors, with amlodipine (79.5\%), perindopril (37.0\%) and atenolol (17.5\%) being the three most commonly prescribed medications to treat hypertension (Table 2).

All participants had a significant reduction in reported blood pressure, with systolic blood pressure reducing from 143.0 (16.0) $\mathrm{mmHg}$ at baseline to 135.3 (14.8) $\mathrm{mmHg}$ at the end of 6 months $(\mathrm{p}<0.001)$. Similarly, diastolic blood pressure reduced significantly from 83.5 (11.7) $\mathrm{mmHg}$ at baseline to $79.0(10.2) \mathrm{mmHg}$ at the end of 6 months $(\mathrm{p}<0.001)$. At follow-up, 61 of 90 patients $(67.8 \%)$ receive monotherapy, 54 of 90 patients $(60.0 \%)$ receiving dual combination therapy and 12 of 20 patients $(60.0 \%)$ receiving triple combination therapy achieved blood pressure goal of less than 140/90 mmHg. A significant drop in systolic and diastolic blood pressure from baseline was demonstrated in patients receiving antihypertensive monotherapy, dual therapy and triple therapy.

Among patients who were prescribed monotherapy, subgroup analysis by ethnicity revealed a significant reduction in systolic blood pressure from baseline to follow-up among Chinese and Malay patients who were prescribed a calcium channel blocker, beta-blocker or angiotensinconverting enzyme inhibitor as well as Chinese patients who were taking a diuretic. There was no significant change in systolic blood pressure from baseline to followup among all ethnic groups who were administering an angiotensin II receptor blocker. 
Table 1. Demographic characteristics of hypertensive patients.

\begin{tabular}{|c|c|c|c|}
\hline & Male & Female & All patients \\
\hline \multicolumn{4}{|l|}{ Age group, years (n) } \\
\hline $21-30$ & 2 & 1 & $3(1.5 \%)$ \\
\hline $31-40$ & 11 & 4 & $15(7.5 \%)$ \\
\hline $41-50$ & 23 & 17 & $40(20.0 \%)$ \\
\hline $51-60$ & 25 & 32 & $57(28.5 \%)$ \\
\hline $61-70$ & 19 & 32 & $51(25.5 \%)$ \\
\hline $71-80$ & 15 & 15 & $30(15.0 \%)$ \\
\hline $81-90$ & 0 & 4 & $4(2.0 \%)$ \\
\hline \multicolumn{4}{|l|}{ Age (years) } \\
\hline Mean (standard deviation) & $55.7(12.9)$ & $59.9(11.6)$ & $57.9(12.4)$ \\
\hline Median (range) & $55(27-78)$ & $60(29-87)$ & 59 \\
\hline \multicolumn{4}{|l|}{ Ethnicity (n) } \\
\hline Malay & 45 & 40 & $85(42.5 \%)$ \\
\hline Chinese & 39 & 49 & $88(44.0 \%)$ \\
\hline Indian & 9 & 13 & $22(11.0 \%)$ \\
\hline Others & 2 & 3 & $5(2.5 \%)$ \\
\hline \multicolumn{4}{|l|}{ Baseline blood pressure (mmHg) } \\
\hline Mean systolic blood pressure (standard deviation) & $142.9(14.4)$ & $143.1(17.4)$ & $143.0(16.0)$ \\
\hline Mean diastolic blood pressure (standard deviation) & $87.6(10.9)$ & $79.9(11.2)$ & $83.5(11.7)$ \\
\hline
\end{tabular}

Table 2. Prescribing frequency of antihypertensive medications.

\begin{tabular}{|c|c|c|c|}
\hline Antihypertensive drug classes & Drug name & Number of patients prescribed & Proportion of patients prescribed \\
\hline \multirow{3}{*}{$\begin{array}{l}\text { Calcium channel blockers }(n=161 \text {, } \\
80.5 \%)\end{array}$} & Amlodipine & 159 & $79.5 \%$ \\
\hline & Felodipine & 1 & $0.5 \%$ \\
\hline & Nifedipine & 1 & $0.5 \%$ \\
\hline \multirow{2}{*}{$\begin{array}{l}\text { Angiotensin-converting enzyme in- } \\
\text { hibitors }(\mathrm{n}=77,38.5 \%)\end{array}$} & Perindopril & 74 & $37.0 \%$ \\
\hline & Enalapril & 3 & $1.5 \%$ \\
\hline \multirow[t]{3}{*}{ Beta-blockers } & Atenolol & 35 & $17.5 \%$ \\
\hline & Metoprolol & 10 & $5.0 \%$ \\
\hline & Bisoprolol & 4 & $2.0 \%$ \\
\hline \multirow[b]{3}{*}{$(\mathrm{n}=27,13.5 \%)$} & Hydrochlorothiazide & 25 & $12.5 \%$ \\
\hline & Hydrochlorothiazide/ Amiloride & 1 & $0.5 \%$ \\
\hline & Frusemide & 1 & $0.5 \%$ \\
\hline \multirow{3}{*}{$\begin{array}{l}\text { Angiotensin II receptor blockers } \\
(\mathrm{n}=15,7.5 \%)\end{array}$} & Losartan & 9 & $4.5 \%$ \\
\hline & Telmisartan & 5 & $2.5 \%$ \\
\hline & Valsartan & 1 & $0.5 \%$ \\
\hline Alpha-blockers $(\mathrm{n}=1,0.5 \%)$ & Prazosin & 1 & $0.5 \%$ \\
\hline
\end{tabular}

\section{Discussion}

A study of prescription patterns is often used to assess medication prescribing practices and forms a basis to improve health care decision making. In this study, we found that the prescribing practice was in line with the Malaysian hypertension guidelines which recommend that either an angiotensin-converting enzyme inhibitor, calcium channel blocker, angiotensin II receptor blocker or diuretic to be used as a first-line agent in uncomplicated hypertension ${ }^{[4]}$. However, this study also observed that beta-blocker was the third most commonly pre- scribed antihypertensive medication. The average number of 1.7 antihypertensive medications per prescription in this study also concurred with reported antihypertensive medications used in developed countries (1.3 to 2.2 drugs per prescription), however, was lower than the values found in developing countries (2.2-3.8 drugs per prescription $)^{[10]}$. This plausibly indicated a leaner and more cost-efficient management of hypertension in Malaysia.

Among the first-line antihypertensive drug classes, diuretic $(13.5 \%)$ and angiotensin II receptor blocker $(7.5 \%)$ were reported to be the least prescribed in this 
study. The low prescription of diuretic could possibly be attributed to fears of adverse metabolic effects, especially hypokalaemia and the resulting adverse effects. The study also noted that the number of antihypertensive medications prescribed was not found to be significantly associated with target blood pressure control. This was in contrast with the findings from a national survey in the United States which noted a $26 \%$ increased likelihood of blood pressure control in patients with multiple-pill combinations ${ }^{[11]}$. The absence of significant association might be due to the relatively small sample size of patients recruited.

There has been some suggestions that Asians may experience a lower efficacy with angiotensin II receptor blockers use, plausibly due to genetic variants in cytochrome P4502C9 enzyme ${ }^{[12]}$. Nevertheless, subgroup analysis performed to explore the differences in antihypertensive drug responses among different ethnic groups found that there was no discernible difference in systolic blood pressure lowering between the groups. This could be caused by the relatively small sample size of patients receiving angiotensin II receptor blocker.

This study has some limitations which warrant attention and further research. Firstly, the study only included a small sample size which made it difficult to identify for any association between variables in certain subgroups of patients. Another limitation of this study was the retrospective design in which any causality was not able to be ascertained and adherence to medications, in particular among older patients, could be a confounding factor affecting the clinical management of hypertension. Hence, further research of sufficiently large sample size is necessary to elucidate the effects of different classes of antihypertensive medications in a multi-ethnic community.

\section{Conclusion}

This study noted that the most commonly prescribed antihypertensive class was calcium channel blockers, specifically amlodipine. There were significant reductions in systolic and diastolic blood pressure at clinic follow-up at 6 months. Future studies should incorporate larger sample size to provide more robust data on medication utilisation in relation to hypertension management in Malaysia.

\section{Conflict of Interest}

The authors declare that there is no conflict of interest in this work.

\section{Funding}

No funding has been received for this research.

\section{Acknowledgments}

All authors would like to thank the Director-General of Health Malaysia for his permission to publish this article. In addition, all authors would also like to express their utmost and sincerest appreciation for the cooperation and support given by Ms. Khairani Azian binti Khairudin and Ms. Ee Boon Cheng from the Department of Pharmacy of Petaling District Health Office, Malaysia. This research would not have been possible without the dedicated guidance and encouragement from them.

\section{Reference}

1. Ab Majid NL, Omar MA, Khoo YY, et al. Prevalence, Awareness, Treatment and Control of hypertension in the Malaysian population: findings from the National Health and Morbidity Survey 2006-2015. J Hum Hypertens 2018; 32(8-9): 617-624.

2. Susic D, and Frohlich ED. Hypertensive cardiovascular and renal disease and target organ damage: lessons from animal models. Cardiorenal Med 2011; 1(3): 139-146.

3. McVeigh GE, Flack J, and Grimm R. Goals of antihypertensive therapy. Drugs 1995; 49(2): 161-175.

4. Malaysian Society of Hypertension, Ministry of Health Malaysia \& Academy of Medicine of Malaysia. Clinical practice guidelines management of hypertension, 5th edition. 2018. http://www.acadmed.org.my/view_file.cfm?fileid=894. Accessed 12 Aug 2019.

5. Nerenberg KA, Zarnke KB, Leung AA, et al. Hypertension Canada's 2018 guidelines for diagnosis, risk assessment, prevention, and treatment of hypertension in adults and children. Can J Cardiol 2018; 34(5): 506-525.

6. Milchak JL, Carter BL, James PA, et al. Measuring adherence to practice guidelines for the management of hypertension: an evaluation of the literature. Hypertension 2004; 44(5): 602-608.

7. Ahmad N, Hassan Y, Tangiisuran B, et al. Guidelines adherence and hypertension control at a tertiary hospital in Malaysia. J Eval Clin Pract 2013; 19(5): 798-804.

8. Myat A, Redwood SR, Qureshi AC, et al. Resistant hypertension. BMJ 2012; 345: e7473.

9. Kahan T. Target blood pressure in patients at high cardiovascular risk. Lancet 2017; 389 (10085): 2170-2172.

10. Abdulameer SA, Sahib MN, Aziz NA, et al. Physician adherence to hypertension treatment guidelines and drug acquisition costs of antihypertensive drugs at the cardiac clinic: A pilot study. Patient Prefer Adherence 2012; 6: 101-108.

11. Gu Q, Burt VL, Dillon CF, et al. Trends in antihypertensive medication use and blood pressure control among United States adults with hypertension: the national health and nutrition examination survey, 2001 to 2010. Circulation 2012; 126(17): 2105-2114.

12. Joy MS, Dornbrook-Lavender K, Blaisdell J, et al. CYP2C9 genotype and pharmacodynamic responses to losartan in patients with primary and secondary kidney diseases. Eur J Clin Pharmacol 2009; 65(9): 947-953. 